\title{
SURGERY BY INFRARED VISION
}

\author{
M. L. Brioschi, \\ O. Malafaia, \\ A. F. C. B. Costa, \\ J. V. Vargas \\ Faculdade Evangélica do Paraná \\ Pos Graduation in Principles of Surgery and \\ Dept of Mechanical Engineering \\ Universidade Federal do Paraná \\ Caixa Postal 19011 \\ 81531-990, Curitiba, Paraná, Brazil \\ termometria@yahoo.com.br
}

\begin{abstract}
This paper is about the development, uses and advantages of infrared thermography. Its principles had already been used by old civilizations as a manner of diseases diagnosis. The discovery of the infrared waves and its heating power happened on 1800 , but its use in modern Medicine as a diagnosis method was only possible because of the scientific and technological development demanded by the Great Wars, in the $20^{\text {th }}$ century. Here the authors present some news and promising surgery applications.
\end{abstract}

\section{INTRODUCTION}

\begin{abstract}
"The 20th century will be remembered for three broad innovations: unprecedented means to save, prolong and enhance life; unprecedented means to destroy life, including for the first time putting our global civilization at risk; and unprecedented insights into the nature of ourselves and the Universe. All three of these developments have been brought forth by science and technology, a sword with two razor-sharp edges. All the three have origin in the distant past."
\end{abstract}

Carl Sagan (1998), Billions and Billion.

The $20^{\text {th }}$ century brings with it the bundle of the wars. From 1914 to 1945 , in exactly thirty one years, humanity witnessed the largest scientific revolution ever seen. The man did, in that period, what had not done in nineteen centuries. At the same time that it caused an enormous destruction in the world, the two great wars brought with it the scientific and technological progress. The most recent example is the use of thermal images (infrared) by the Coalition Air Forces, which spilled against Iraq attacks of high precision with intelligent weapons guided by the heat. Thanks to the high resolution and sensibility infrared vision technology, today it is possible to esteem the coronarian flow during the operation of revascularization of the myocardium, observed by distance and in a totally non-invasive way (Brioschi et al., 2002). This is of great help to increase the surgical success tax and the final quality of service to the coronary patient.

Since the Antiquity it is known that the body produces heat and that its degree increases during infections and diseases. The Egyptians didn't use infrared cameras or thermometers, just the sensibility of their fingers to monitor the superficial temperature of the body. The fingers were used as scanners and the brain as a computer. They interpreted and described the increase of the temperature in wounds, tumors or in the whole body, as well as its elevation through the days (Medical Thermology, 1986).

Hypocrates wrote 400 B.C.: "In any part of the body where there is excess of heat or cold, the disease it will be there to be discovered". The old Greek immersed the body in mud and the area that dried faster, indicating the warmest area, was considered sick (Hodge Jr., 1987).

Sir William Herschel, an astronomer, discovered the infrared in 1800. He built his own telescopes becoming, therefore, quite familiarized with lenses and mirrors. Knowing that the solar light contained all the spectrum colors and that it was also a source of heat, Herschel wanted to discover which colors were responsible by heating the objects. He idealized an experiment using a prism, cardboard and thermometers with black bulbs in which he measured the temperatures of different colors. Herschel observed a temperature increase as he moved the thermometer from violet to red in the spectrum created by the sunlight crossing the prism. He discovered that the hottest temperature happened, in fact, over the red light. The radiation that caused that heating was not visible; Herschel denominated that invisible radiation as "calorific" rays. Today, it is known as infrared (Medical Thermology, 1986).

During World War II there was a development of infrared detection technology for strictly soldierly use. By the end of the fifties this technology was liberated for research seeking civil use, but still under severe surveillance and restrictions. Lloyd-Williams (1961), in Lancet journal, got attention on the possibilities of the infrared radiation detection and measuring with diagnose purposes use in Medicine, demonstrating the temperature increase in breast tumors.

Thermography was very extolled exam in the seventies for the detection of malignant breast tumors, 
other superficial and soft tissue tumors, articulation inflammatory diseases, vasculopathy and other less frequent applications, but it got in disuse due to factors as: progresses of the mammography technique and other diagnoses methods, larger installed base of radiological apparatus, the radiologists' larger experience in the visualization of mammography images than in the obtaining of thermograms in a static way.

This technology grew widely in the military range, in cameras, binoculars and other workmanships of night surveillance, missiles detectors in airplanes, earth-air missiles sensors, spy satellites and meteorological observation satellites sensors. This contributed to a smaller use and evolution of thermography in the medical field.

After the eighties, with the development of faster computers and more powerful programs in the data processing and mainly complex images, it was possible to understand that thermography should be seen as a functional and dynamic exam and not as a conventional radiological exam which is anatomical and static. In 1990, the United States, through FDA (Food and Drug Administration), recognized infrared thermography as a valid complementary diagnosis method for the medical practice.

From this time on, its use in surgery has increased, especially in the evaluation of the organs and tissues microcirculation. Unlike what happens in corporal surface, the internal organs are not wrapped up by a thermal insulator. According to Newton's third law, they get cold once exposed to cold places. The temperature is determined basically by the flow of the blood perfusion organ (Brioschi et al., 2000). For this reason, the heart muscle viability can be evaluated by the continuous registration of thermal images of the heart. In case there is an arterial net in certain organ and the warm blood supplies this net, its anatomical pattern is clearly observed in thermal images. The arterial coronarian net exists in the heart surface (epicardium). When the hemostatic is liberated after the accomplishment of the anastomosis, the warm blood pattern can be observed flowing to $4^{\text {th }}$ order branches of the coronary arteries, as shown in Fig. 1 (Suma et al., 2000). Because of its countless advantages, it is a likely candidate for becoming an indispensable tool for a safe myocardic revascularization. The same principle is already used in the intra-operative evaluation of the intestinal viability, showing to be safer than the fluoresceine (Moss et al., 1981; Brooks et al., 2001; Kreyer et al., 1989) equally in the viability of cutaneous grafts and in determination of the limbs amputation level.

It has been used in kidney, liver, lung and intestines transplants, in the postoperative evaluation to check the presence of venous thrombosis (Brunkwall et al., 1987), acute rejection (Klar et al., 1999) and immunosupression drugs toxicity (Doutreleau et al., 2001)

It is the recent developed method for laparoscopic surgery where through an optical pair, visible light and infrared, it is possible to identify just by heat waves, anatomical structures before dissecting them, like cystic artery and ureter. Besides, it evaluates the limits of the intestinal ressection during enterectomies (Roberts et al., 1997).

Thanks to the human body infrared imaging, externally and internally, the new millennium surgeon is reestablishing, besides the normal anatomy of the tissues and organs, also the physiological working of the same ones, with more precision. This method is already included in the list of procedures of the Brazilian Medical Association (AMB 39.01.007-4).

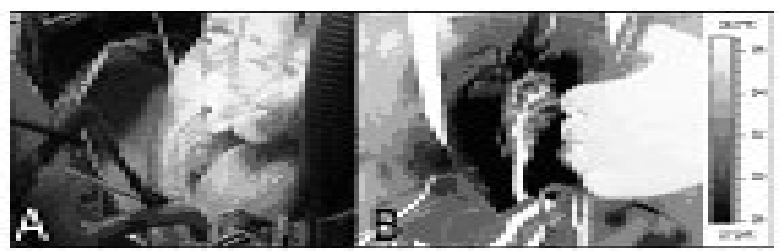

Figure 1. Evaluation of the posterior heart wall perfusion with intra-operative thermo-coronary-angiography after unclamping the graft for diagonal coronary artery.

\section{REFERENCES}

Sagan, C., 1998, Bilhões e bilhões - Reflexões sobre vida e morte na virada do milênio (in Portuguese) São Paulo, Companhia das Letras.

Brioschi, M. L., Cimbalista Jr., M., Colman, D. et al., "Termo-coronário-angiografia: padronização do método e primeiras aplicações clínicas no Brasil"' (in Portuguese) Rev Bras Cir Cardiovasc. [online]. abr./jun. 2002, Vol. 17, No. 2, p.123-127. (http://www.scielo.br/scielo.php?script $=$ sci_arttext\&pid $=\mathrm{S}$ 0102-76382002000200004\&lng=pt\&nrm=isso).

Medical Thermology, 1986, American Academy of Thermology, Georgetown University Medical Center, Washington D.C., p. 1.

Hodge Jr., S., 1987, Thermography \& Personal Injury Litigation, Wiley Law Publications, p. 71.

Lloyd-Williams, K, Handley, R. S., 1961, "Infra-red thermometry in the diagnosis of breast disease", Lancet, Vol. 2, pp. 1378-1381.

Brioschi, M. L., Cimbalista Jr., M., Nakagawa, C. R., et al., 2000, "Avaliação intraoperatória da revascularização cardíaca por angiografia térmica coronária: estudo experimental preliminar", Arq Med PUCPR, Vol. 2, p. 33.

Suma, H., Isomura, T., Horii, T., et al., 2000, "Intraoperative coronary artery imaging with infrared camera in off-pump CABG", Ann Thorac Surg, Vol. 70, pp. 1741-1742. 
Moss, A. A, Kressel, H. Y., Brito, A. C., 1981, "Use of thermography to predict intestinal viability and survival after ischemic injury: a blind experimental study", Inv Radiol, Vol. 16, pp. 24-29.

Brooks, J. P., Perry, W. B., Putnam, A. T., et al., 2001, "Thermal imaging in the detection of bowel ischemia" Dis Colon Rectum, Vol. 43, No. 9, pp. 1319-1321.

Kreyer, I., Lehmann, C., Kekesi, V. et al., 1989, "Motility, haemodynamics and responsibility to vasoactive agents after revascularization of autotransplanted small intestine segments in the dog", Acta Chir Hung, Vol. 30, No. 4, pp. 261-271.

Brunkwall, J., Bergqvist, D., Bergentz, S. E., et al., 1987, "Postoperative deep venous thrombosis after renal transplantation", Effects of cyclosporine. Transplantation, May; Vol. 43, No. 5, pp. 647-649.

Klar, E., Angelescu, M., Zapletal, C., et al., 1999, "Impairment of hepatic microcirculation as an early manifestation of acute rejection after clinical liver transplantation", Transplant Proc., Feb-Mar, Vol. 31, No. (1-2), pp. 385-387.

Doutreleau, S., Gautherie, M., Lonsdorfer, E., et al., 2001, "Usefulness of finger thermography to assess cyclosporine toxicity after heart transplantation", Transplant Proc, Nov-Dec, Vol. 33, No. (7-8), pp. 33183319.

Roberts, W. W., Dinkel, T. A., Schulam, P. G., et al., 1997, "Laparoscopic infrared imaging", Surg Endosc, Dec, Vol. 11, No. 12, pp. 1221-1223. 